\title{
Susceptibility to ATP depletion of primary proximal tubular cell cultures derived from mice lacking either the $a 1$ or the $a 2$ isoform of the catalytic domain of AMPK
}

Wilfred Lieberthal ${ }^{1,2^{*}}$, Meiyi Tang ${ }^{1,2}$, Leiqing Zhang ${ }^{1,2}$, Benoit Viollet ${ }^{3,4,5}$, Vimal Patel ${ }^{6,7}$ and Jerrold S Levine B, $^{6,7}$

\begin{abstract}
Background: The purpose of this study was to determine whether AMPK influences the survival of primary cultures of mouse proximal tubular (MPT) cells subjected to metabolic stress. Previous studies, using an immortalized MPT cell line, suggest that AMPK is activated during metabolic stress, and ameliorates stress-induced apoptosis of these cells.

Methods: Primary MPT cells were cultured from AMPK knockout $(K O)$ mice lacking either the a1 or the a2 isoform of the catalytic domain of AMPK. MPT cells were subjected to ATP depletion using antimycin A.

Results: Surprisingly, there was no difference in the amount of death induced by metabolic stress of MPT cells from either type of AMPK KO mice compared to its WT control. Moreover, inhibition of the activity of the a1 isoform in primary MPT cells from $\mathrm{a}^{-/-}$mice (pharmacologically, via compound C) or inhibition of the $\mathrm{a} 2$ isoform in primary MPT cells from $a 1^{-/-}$mice (molecularly, via knockdown) both decreased cell viability equivalently in response to metabolic stress. The explanation for this unexpected result appears to be an adaptive increase in expression of the non-deleted a-isoform. As a consequence, total a-domain expression (i.e. a1 $+a 2$ ), is comparable in kidney cortex and in cultured MPT cells derived from either type of KO mouse versus its WT control. Importantly, each a-isoform appears able to compensate fully for the absence of the other, with respect to both the phosphorylation of downstream targets of AMPK and the amelioration of stress-induced cell death.

Conclusions: These findings not only confirm the importance of AMPK as a pro-survival kinase in MPT cells during metabolic stress, but also show, for the first time, that each of the two a-isoforms can substitute for the other in MPT cells from AMPK KO mice with regard to amelioration of stress-induced loss of cell viability.
\end{abstract}

Keywords: AMPK, Viability, Survival, Apoptosis knockout mice, shRNA, ATP depletion, Metabolic stress, Antimycin

\section{Background}

AMP-activated protein kinase (AMPK) is a ubiquitously expressed and highly conserved serine/threonine kinase that is activated by any form of stress that reduces cell energy stores $[1,2]$. AMPK is a heterotrimeric protein composed of a catalytic $\alpha$ subunit and two regulatory $(\beta$ and $\gamma$ ) subunits [1]. There are two isoforms of the

\footnotetext{
* Correspondence: wilfred.lieberthal@stonybrookmedicine.edu 'Department of Medicine, Stony Brook University Medical Center, Stony Brook, NY 11794, USA

${ }^{2}$ Northport Veterans Affairs Medical Center, Northport, NY 11768, USA Full list of author information is available at the end of the article
}

catalytic ( $\alpha 1$ and $\alpha 2)$ and $\beta$ ( $\beta 1$ and $\beta 2)$ subunits, and three isoforms of the $\gamma(\gamma 1, \gamma 2$, and $\gamma 3)$ subunit, all of which are encoded by different genes [1]. AMPK is activated by phosphorylation of a threonine residue $\left(\mathrm{Thr}^{172}\right)$ situated within the activation loop of the $\alpha$-subunit [3-5]. The best-defined upstream AMPK kinase is liver kinase B1 (LKB1). LKB1 is constitutively active, so that AMPK is continuously being phosphorylated [3-5]. When cell energy stores are replete, AMPK is maintained in an inactive state by the activity of phosphatases such as phosphatase-2C alpha [1,3,4]. Activation of AMPK occurs whenever cell stress leads to a decrease in

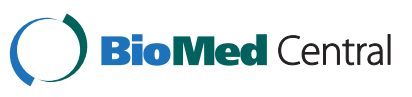


cytosolic ATP levels and a concomitant increase in levels of adenosine diphosphate (ADP) and adenosine monophosphate (AMP) [3,4]. The regulatory $\gamma$-subunit of AMPK has binding sites for all three nucleotides [6,7]. Binding of ADP or AMP to the $\gamma$-subunit activates AMPK via two mechanisms, inhibition of the dephosphorylation of $\mathrm{Thr}^{172}$ and allosteric facilitation of phosphorylation of AMPK by LKB1 [3,4]. In contrast to the effects of ADP and AMP, binding of ATP to the $\gamma$ subunit of AMPK promotes its deactivation $[1,3,4]$. The net result of these opposing interactions is that AMPK activity is inversely related to the ratio of the concentration of ATP to that of ADP and AMP [3,4,7].

Upon activation, AMPK phosphorylates and alters the activity of multiple downstream kinases and enzymes $[8,9]$. AMPK also induces changes in gene expression [10]. Together, these effects of AMPK lead to alterations in glucose, protein, and lipid metabolism that serve to conserve energy stores by promoting ATP production, inhibiting ATP consumption, and facilitating the cellular uptake of nutrients $[1,2,8,9,11,12]$. For example, through phosphorylation and inhibition of acetyl-CoA carboxylase 1 (ACC1) and ACC2, AMPK inhibits lipid synthesis and promotes fatty acid oxidation [1,13-15]. By inhibiting the activity of the mammalian target of rapamycin (mTOR), AMPK also inhibits protein synthesis [16,17]. Other AMPK-mediated effects include increased cellular uptake of glucose and fatty acids, and increased glycolysis [9].

Recently, using an immortalized mouse proximal tubular (MPT) cell line, we have shown that AMPK is activated by ATP depletion, and that, once activated, AMPK ameliorates apoptosis induced by this form of stress [18]. Here we extend these findings to primary cultures of MPT cells, derived from the kidneys of AMPK knockout $(\mathrm{KO})$ mice with whole body deletions of either the $\alpha 1\left(\alpha 1^{-/-}\right)$or the $\alpha 2\left(\alpha 2^{-/-}\right)$isoforms of AMPK. We hypothesized that primary MPT cells, lacking one or other of the $\alpha$-isoforms of AMPK, should be more susceptible to apoptosis induced by ATP depletion than primary MPT cells with both $\alpha$-isoforms intact. Surprisingly, we found no difference in the severity of antimycin-induced cell death in MPT cells from $\alpha 1^{-/-}$or $\alpha 2^{-/-}$mice versus their WT controls. Moreover, we found that a reduction of AMPK activity (via either pharmacologic inhibition or knockdown of one of the $\alpha$-isoforms) led to comparable increases of antimycin-induced apoptosis in primary MPT cells from KO versus WT mice.

In explaining this absence of a difference in stressinduced apoptosis for MPT cells from KO versus WT mice, we show that there is a compensatory up-regulation in expression of the intact $\alpha$-isoform in both AMPK KO mice. This up-regulation compensates fully for the deleted $\alpha$-isoform, such that the total amount of $\alpha$-domain protein is comparable in primary MPT cells from the two $\mathrm{KO}$ mice versus their WT controls. These findings not only confirm the importance of AMPK activation as a pro-survival kinase during ATP depletion, but also indicate that each of the two $\alpha$-isoforms can substitute for the other in ameliorating the consequences of metabolic stress.

\section{Methods \\ Materials}

All chemicals were purchased from Sigma (MO) unless otherwise stated. Soybean trypsin inhibitor was purchased from GIBCO (NY). Rabbit polyclonal antibody to total AMPK, rabbit polyclonal antibody to total alpha subunit of AMPK, and mouse monoclonal antibody to the phosphorylated alpha subunit of AMPK were purchased from Cell Signaling Technologies (MA). Rabbit polyclonal antibody to phosphorylated ACC1/2 was purchased from Upstate (NY). Rabbit polyclonal antibodies specific for the $\alpha 1$ and $\alpha 2$ isoforms of the catalytic domain of AMPK were purchased from Abcam (MA). Monoclonal antibody to $\beta$ actin was purchased from Chemicon (CA).

\section{Mice}

The generation and phenotype of whole body $\alpha 1^{-/-}$and $\alpha 2^{-/-}$KO mice have been described previously $[19,20]$. $\alpha 1^{-1-}$ mice and their WT controls were bred on a mixed background (C57BL6J/129Sv), whereas $\alpha 2^{-/-} \mathrm{KO}$ mice and their WT controls were bred on a C57BL6J background. Heterozygous $\alpha 1^{-/-}$and $-\alpha 2^{-/-}$KO mice, used only for breeding, were obtained from the European Mouse Mutant Archive and bred in the Department for Laboratory and Animal Research at Stony Brook Hospital. Only homozygous $\mathrm{KO}$ mice, male and female, were used for experimentation. All studies were approved by the IACUC at Stony Brook Hospital. Total body weights and kidney weights were comparable amongst $\mathrm{KO}$ and WT mice (data not shown).

\section{Primary culture of mouse proximal tubular (MPT) cells}

Techniques for the primary culture of MPT cells are well established in our laboratory [21,22]. Briefly, kidneys were harvested from mice at 4-6 weeks of age. Cortical tissue was finely minced and incubated in Hanks's solution containing collagenase and soybean trypsin inhibitor. After collagenase digestion, 10\% horse serum was added, and the tissue fragments were gently centrifuged. After two washes with DMEM, tissue fragments were suspended in growth medium, a serum-free, defined medium consisting of DMEM/Ham's F-12 media (1:1) containing $2 \mathrm{mM}$ glutamine, $15 \mathrm{mM}$ HEPES ( $\mathrm{pH} 7.2), 5 \mu \mathrm{g} / \mathrm{ml}$ transferrin, $5 \mu \mathrm{g} / \mathrm{ml}$ insulin, $50 \mathrm{mM}$ hydrocortisone, $500 \mathrm{U} / \mathrm{ml}$ penicillin, and $50 \mathrm{mg} / \mathrm{ml}$ streptomycin. The tissue fragments, suspended in growth medium, were then plated on plastic tissue cultures plates and incubated in a humidified air $/ \mathrm{CO}_{2}$ incubator $(5 \% \mathrm{v} / \mathrm{v})$ at $37^{\circ} \mathrm{C}$. 
Fragments of tubules adhere to the culture dish, and MPT cells grow out of the tubules to form confluent monolayers over a 4-5 day period. MPT cells express megalin and other markers specific for proximal tubular cells. Five days after plating, the medium was changed to experimental medium, which consists of DMEM/Hams F12 containing HEPES ( $\mathrm{pH}$ 7.2), $15 \mathrm{mM}$ glutamine, 500 $\mathrm{U} / \mathrm{ml}$ penicillin, and $50 \mathrm{mg} / \mathrm{ml}$ streptomycin. No insulin, hydrocortisone, or transferrin was added to this medium. Experiments were begun on the sixth day after plating.

\section{Metabolic stress (graded ATP depletion)}

MPT cells were exposed to metabolic stress using antimycin A, a mitochondrial inhibitor. We examined the effect of antimycin A in the presence of three concentrations of dextrose, 10,5 , and $2.5 \mathrm{mM}$. The severity of metabolic stress increases progressively, (i.e. cell ATP levels fall progressively), as the dextrose concentration in the medium is reduced from 10 to $2.5 \mathrm{mM}$. We refer to this model of metabolic stress as "graded" ATP depletion. We have used graded ATP depletion as a model of metabolic stress in previous publications [22]. Control (unstressed) MPT cells were incubated in $5 \mathrm{mM}$ dextrose in the absence of antimycin.

\section{Cell ATP levels}

ATP levels were determined using previously described methods [22]. Briefly, cell ATP content was measured by luciferase assay in cell lysates and normalized to total cellular protein, as assessed by bicinchoninic acid (BCA) protein assay (Pierce, Rockford, NY). Control ATP levels, obtained in cells incubated in dextrose-containing medium (5 $\mathrm{mM})$ in the absence of antimycin, were expressed as nanomoles of ATP per milligram of cell protein (nM ATP/mg protein). ATP levels obtained during metabolic stress were expressed as a percentage of ATP levels under control conditions.

\section{Immunoblotting}

Immunoblotting was performed as previously described [23]. Briefly, cells were washed with ice-cold PBS, then lysed in ice-cold cell lysis buffer $(20 \mathrm{mM}$ Tris- $\mathrm{HCl}$, $\mathrm{pH} 7.5$, containing $130 \mathrm{mM} \mathrm{NaCl}, 1 \% \mathrm{v} / \mathrm{v}$ Triton X-100, $0.5 \% \mathrm{w} / \mathrm{v}$ deoxycholate, $0.1 \% \mathrm{w} / \mathrm{v}$ SDS, $1 \mathrm{mM}$ DTT, $10 \mathrm{mM}$ sodium pyrophosphate, $5 \mathrm{mM}$ sodium fluoride, $1 \mathrm{mM}$ phenylmethylsulfonyl fluoride, and $200 \mu \mathrm{M}$ sodium orthovanadate). Lysates were centrifuged at 10,000 $\times g$ for $10 \mathrm{~min}$ at $4^{\circ} \mathrm{C}$, and the supernatants were stored at $-70^{\circ} \mathrm{C}$. Protein samples, $20 \mu \mathrm{g}$ per lane, as determined by $\mathrm{BCA}$ protein assay, were boiled in $6 \times$ reducing sample buffer, electrophoresed on SDS-polyacrylamide gels, and transferred to nitrocellulose membranes (BIO-RAD, Hercules, CA). Membranes were blocked with either 2.5\% bovine serum albumin or 5\% dry milk in TBS, before probing with primary antibody. After incubation with the appropriate secondary antibody, immunoreactive bands were visualized by the Western Lightning Chemiluminescence Reagent Plus (PerkinElmer, Boston, MA).
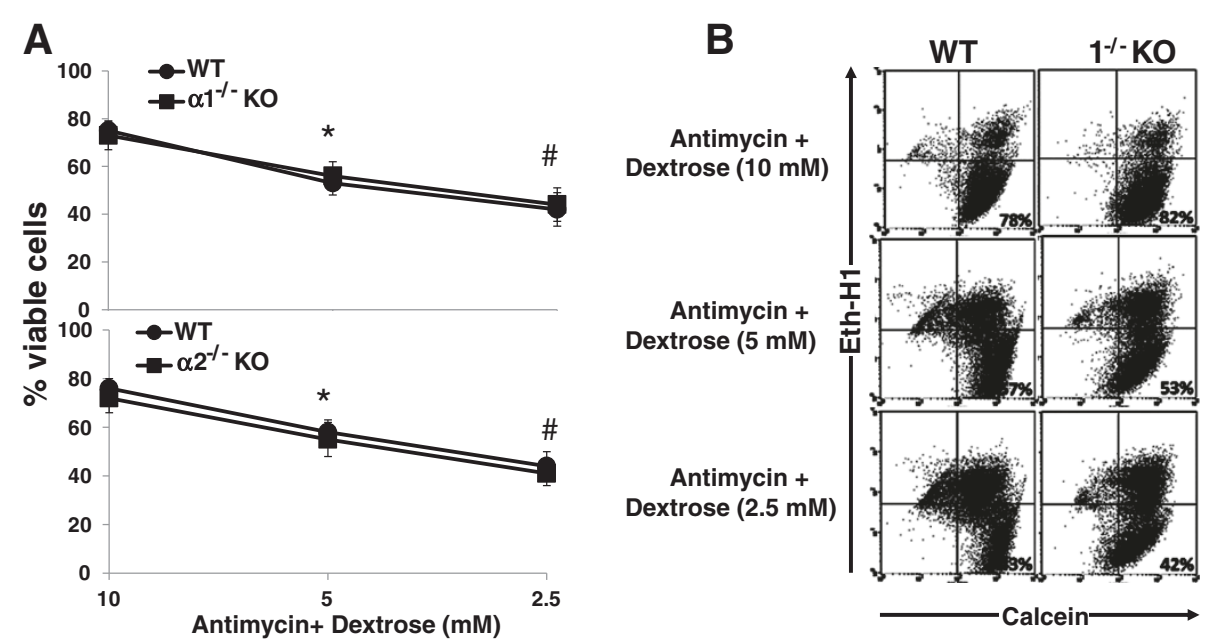

Figure 1 Effect of metabolic stress on the viability of MPT cells from $\mathbf{a} 1^{-/-}$and $\mathbf{a} \mathbf{2}^{-/-}$KO mice. A: MPT cells from a $1^{-/-}$mice (upper panel) or $\mathrm{a}^{-1-} \mathrm{KO}$ mice (lower panel), or their WT controls, were subjected to graded metabolic stress by incubation in the presence of antimycin $(2 \mu \mathrm{M})$ and varying concentrations of dextrose. After 16-18 hrs, the percentage of viable cells remaining was determined by flow cytometry ( $n=5$ for both experiments). * $p<0.02,5 \mathrm{mM}$ dextrose vs. $10 \mathrm{mM}$ dextrose; \# $p<0.02,2.5 \mathrm{mM}$ dextrose vs. $5 \mathrm{mM}$ dextrose. B: Representative flow cytometric analysis of MPT cells from $\mathrm{a1}^{-1-}$ mice (right panels) and their WT control (left panels) incubated in antimycin $(2 \mu \mathrm{M})$ plus varying concentrations of dextrose. Cell viability was quantified by staining cells with calcein AM (x-axis) and ethidium homodimer-1 (Eth-H1) (y-axis). For each condition, 10,000 cells were analyzed, and the percentage of viable cells was calculated by dividing the number of calcein-positive and Eth-H1-negative cells by the total number of cells counted. 


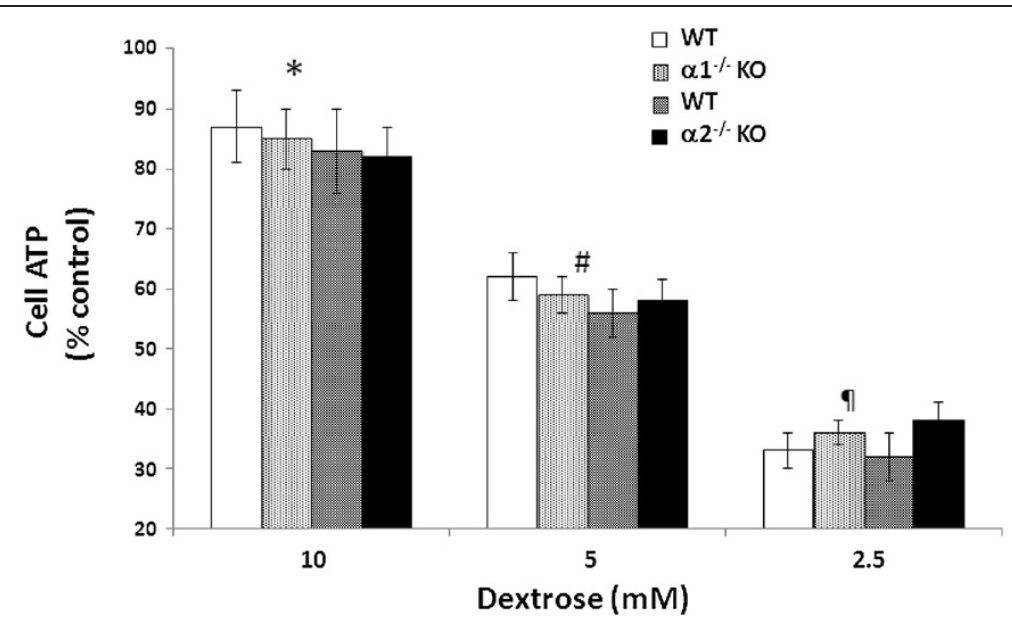

Figure 2 Effect of metabolic stress on cytosolic ATP levels in MPT cells from $\mathbf{a}^{-/-}$and $\mathbf{a}^{-\mathbf{2}^{--}} \mathrm{KO}$ mice. MPT cells from $\mathrm{a1^{-/- }}$ mice or $\mathrm{a} 2^{-/-} \mathrm{KO}$ mice, or their WT controls, were subjected to graded ATP depletion by incubation in the presence of antimycin $(2 \mu \mathrm{M})$ and varying concentrations of dextrose for 4 hrs. Cell ATP levels were measured and normalized to cell protein content. All values are expressed as a percent of ATP levels in MPT cells incubated under control conditions (10 mM dextrose, in the absence of antimycin). ${ }^{*} p<0.02$, antimycin plus $10 \mathrm{mM}$ dextrose vs. control conditions; \# $p<0.01$, antimycin plus $5 \mathrm{mM}$ dextrose vs. antimycin plus $10 \mathrm{mM}$ dextrose; $p<0.01$, antimycin plus $2.5 \mathrm{mM}$ dextrose vs. antimycin plus $5 \mathrm{mM}$ dextrose.

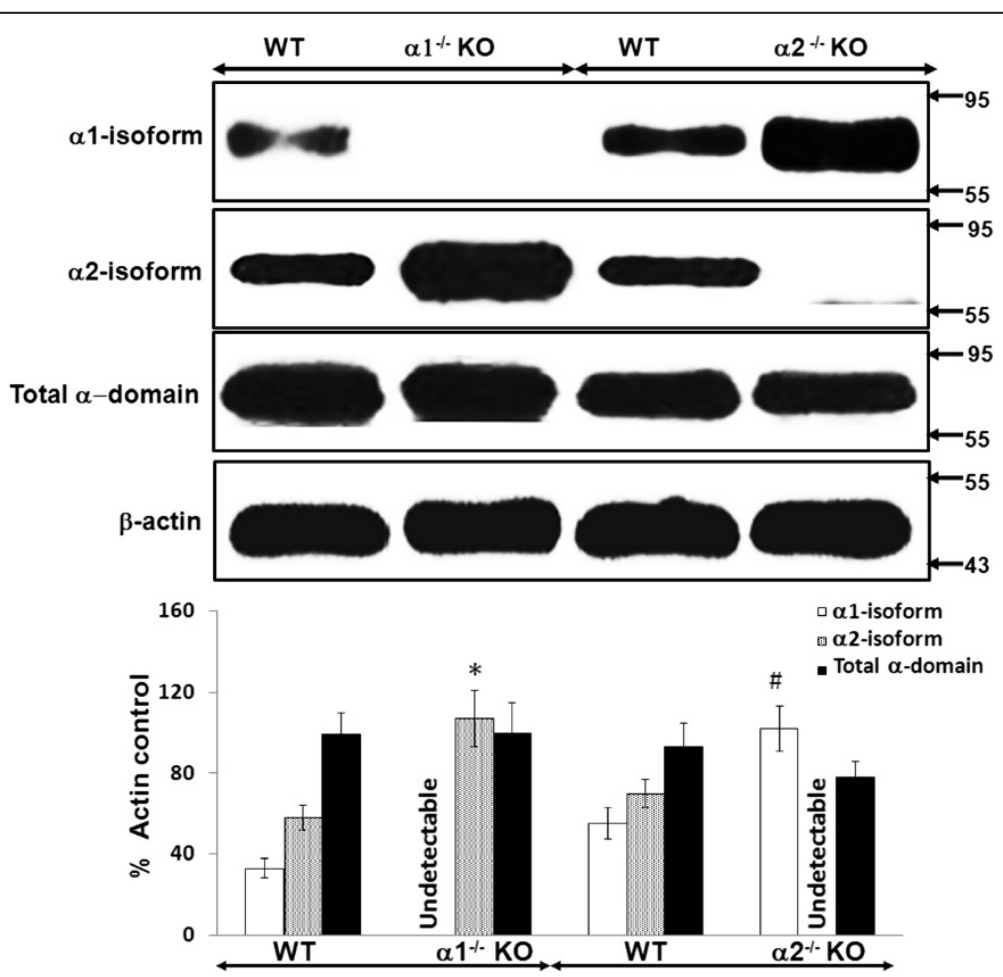

Figure 3 Relative expression of the catalytic alpha (a) domain of AMPK in whole kidney cortex obtained from $a 1^{-/-}$and $a 2^{-/-}$ knockout (KO). The relative expression of the $a 1$ and $a 2$ isoforms of AMPK, and of the total $a(a 1+a 2)$ domain, was evaluated in immunoblots of lysates of "snap frozen" samples of kidney cortex, obtained from $\mathrm{a}^{-/-}$or $\mathrm{a}^{-/-} \mathrm{KO}$ mice and their WT controls. Upper panel: Representative immunoblot. Molecular weight markers (in $\mathrm{kDa}$ ) are shown on the right of each immunoblot. Lower panel: Densitometric quantitation of three immunoblots using $\beta$-actin as a loading control. ${ }^{*} p<0.01, a 1^{-1-}$ vs. WT mice, for a2 isoform expression; \# $p<0.02, a 2^{-1-}$ vs. WT mice, for a1 isoform expression. 


\section{Cell viability}

Cell viability was determined using the LIVE/DEAD Assay Kit purchased from Molecular Probes ${ }^{\mathrm{ma}}$ and used according to the manufacturer's instructions. In brief, MPT cells were stained with ethidium homodimer-1 (EthD-1) and calcein AM. Live cells are identified by their ability to convert calcein AM, a non-fluorescent cell-permeant agent to calcein, an intensely fluorescent dye (excitation/emission wavelengths, $\sim 495 \mathrm{~nm} / \sim 515 \mathrm{~nm}$ ) that is retained within live cells. Dead cells are identified by nuclear staining for EthD-1, which only enters cells with damaged plasma membranes and, upon binding to nucleic acids, undergoes a 40-fold enhancement of fluorescence (excitation/emission wavelengths, $495 \mathrm{~nm} /$ $\sim 635 \mathrm{~nm}$ ), thereby producing a bright fluorescence in dead cells. Since both dyes are essentially non-fluorescent before interacting with cells, background fluorescence is inherently low. Live and dead cells were quantitated using flow cytometry (FACScan, BD Biosciences), and data were analyzed using CELLQuestPro Version 3.3 (BD Biosciences). Cells were first analyzed by forward versus side scatter, and gated to remove debris, cell fragments, and cell aggregates. The proportion of live cells in each sample was expressed as a percent of the total number of cells analyzed (10,000/sample).

\section{Statistics}

All data are presented as mean \pm standard error (SE). Student's t-test was used for comparing cell ATP levels and densitometry of immunoblots. The Bonferroni correction was applied when multiple comparisons were made. The viability of MPT cells cultured from $\mathrm{KO}$ versus WT mice and subjected to metabolic stress was compared by ANOVA for repeated measures using $\mathrm{STATA}^{\circ}$ Data Analysis and Statistical Software. All p values $<0.05$ were considered statistically significant.

\section{Results}

Effect of metabolic stress on the viability of MPT cells from $\mathrm{a} 1^{-/-}$and $\mathrm{a} 2^{-/-}$versus WT mice

We determined the effect of graded ATP depletion, induced by exposing MPT cells to antimycin A and varying concentrations of dextrose, on cell viability, as assessed by flow cytometry. Cell viability was comparable in MPT cells from $\mathrm{KO}$ versus WT mice under unstressed control conditions (10 mM dextrose, no antimycin) (data not shown).

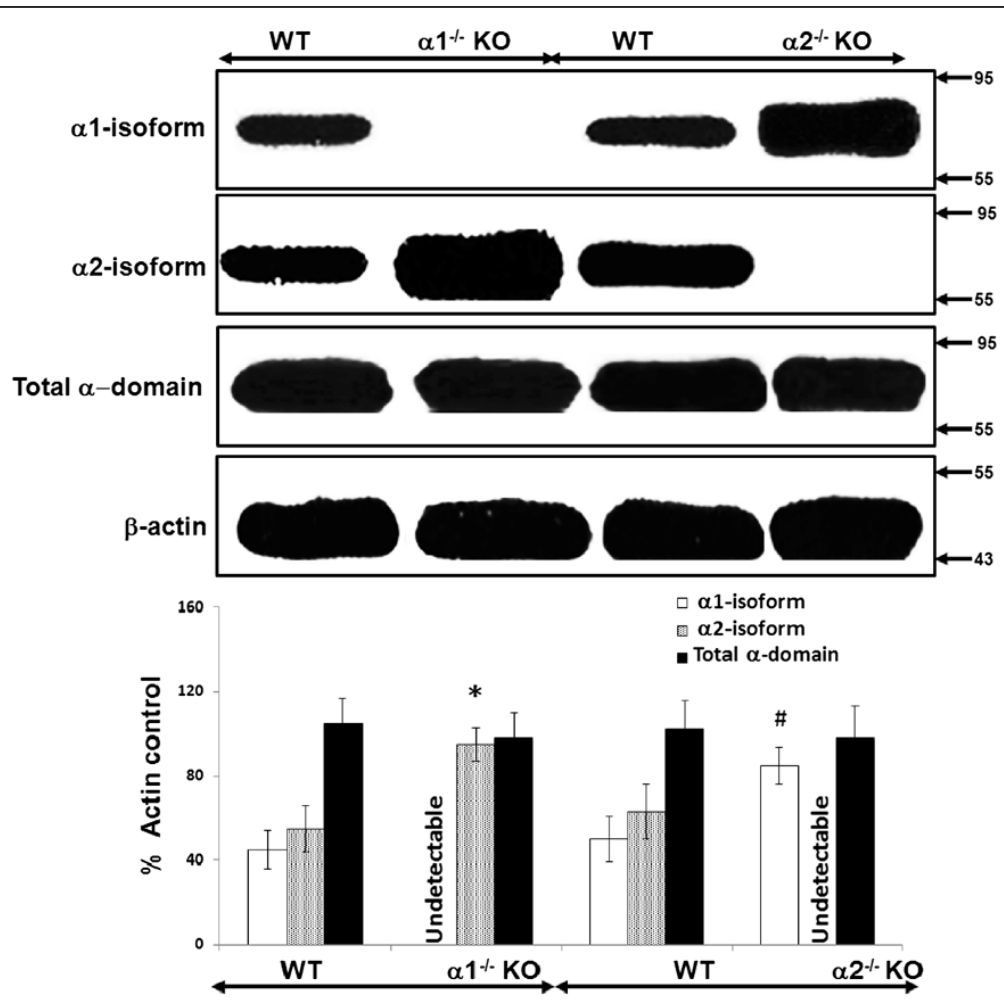

Figure 4 Relative expression of the catalytic alpha (a) domain of AMPK in proximal tubular cells derived from $a 1^{-/-}$and $a 2^{-/-}$ knockout (KO) mice. The relative expression of the $a 1$ and a2 isoforms of AMPK, as well as of the total a domain ( $a 1+a 2)$, was evaluated in immunoblots of lysates from confluent mouse proximal tubular (MPT) cells derived from the kidneys of either $a 1^{-/-}$or $a 2^{-/-} \mathrm{KO}$ mice, or their WT controls. Upper panel: Representative immunoblot. Molecular weight markers (in kDa) are shown on the right of each immunoblot. Lower panel: Densitometric quantitation of three immunoblots using $\beta$-actin as a loading control. ${ }^{*} p<0.02, a 1^{-1-}$ vs. WT mice, for a2 isoform expression; $\# p<0.02, a 2^{-1-}$ vs. WT mice, for a1 isoform expression. 
In the presence of antimycin, the percentage of viable MPT cells from AMPK KO and WT mice decreased progressively as the concentration of dextrose was decreased (Figure 1). Nevertheless, at each dextrose concentration, the survival of MPT cells from $\alpha 1^{-/-}$or $\alpha 2^{-/-}$KO mice was no different than that of MPT cells from WT controls (Figure 1).

\section{Effect of metabolic stress on cytosolic ATP levels in MPT} cells from $a 1^{-/-}$and $a 2^{-/-}$mice

Cytosolic ATP levels in control unstressed MPT cells incubated in $10 \mathrm{mM}$ dextrose without antimycin for $4 \mathrm{hrs}$ were no different for KO versus WT controls (21 \pm 8 $\mathrm{nM} / \mathrm{mg}$ protein versus $23 \pm 6 \mathrm{nM} / \mathrm{mg}$ protein for $\alpha 1^{-/-}$ mice; and $26 \pm 9 \mathrm{nM} / \mathrm{mg}$ protein versus $21 \pm 7 \mathrm{nM} / \mathrm{mg}$ protein for $\alpha 2^{-/-}$mice). Incubation of MPT cells in the presence of antimycin for $4 \mathrm{hrs}$ led to a reduction in ATP levels. The severity of ATP depletion was inversely proportional to the concentration of dextrose in the medium (Figure 2). However, the severity of ATP depletion did not differ in MPT cells from $\mathrm{KO}$ versus WT mice at any dextrose concentration (Figure 2).

Relative expression of the catalytic alpha domains of AMPK in whole kidney cortex and in cultured proximal tubular cells obtained from $a 1^{-/-}$and $a 2^{-/-} \mathrm{KO}$ and WT mice We used immunoblotting to determine the relative expression of the $\alpha 1$ and $\alpha 2$ isoforms of AMPK, as well as total $\alpha$ domain expression ( $\alpha 1+\alpha 2$ isoforms), in lysates obtained from whole kidney cortex (Figure 3 ) and confluent monolayers of MPT cells (Figure 4), both derived from AMPK KO mice and their WT controls. As expected, we detected no expression of the deleted $\alpha 1$ or $\alpha 2$ isoform in lysates from either whole kidney cortex (Figure 3) or MPT cell cultures (Figure 4) obtained from the $\alpha 1^{-/-}$and $\alpha 2^{-/-}$mice, respectively. Notably, however, expression of the non-deleted $\alpha$-isoform was markedly increased in kidney cortex and MPT cell cultures from AMPK KO mice when compared to their WT controls (Figures 3 and 4). As a result, total alpha domain

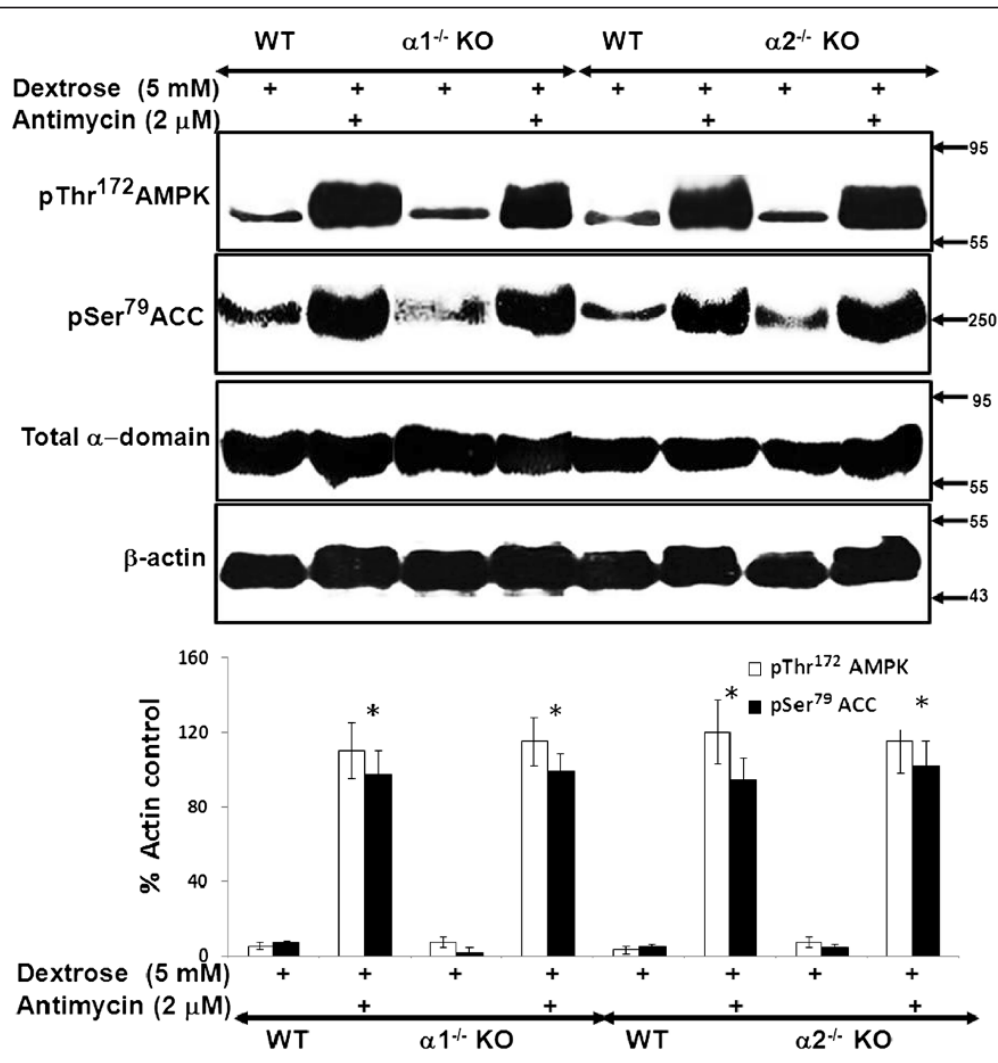

Figure 5 Effect of metabolic stress on activation of the AMPK pathway in MPT cells from $\mathrm{a}^{-1_{-}^{-}}$and $\mathrm{a}^{-/-} \mathrm{KO}$ mice. MPT cells obtained from $\mathrm{a}^{-/-}$or $\mathrm{a} 2^{-/-} \mathrm{KO}$ mice, or their WT controls, were subjected to metabolic stress by incubation in medium containing dextrose (5 mM) plus antimycin $(2 \mu \mathrm{M})$ for $4 \mathrm{hrs}$. Control cells were incubated in dextrose in the absence of antimycin. Activation of the AMPK pathway was assessed by immunoblotting using antibodies that recognize either the phosphorylated (activated) form of AMPK or the phosphorylated (inhibited) form of acetyl coenzyme A carboxylase (ACC). Expression of total AMPK was also assessed. Upper panel: Representative immunoblot. Molecular weight markers (in $\mathrm{kDa}$ ) are shown on the right of each immunoblot. Lower panel: Densitometric quantitation of three immunoblots using $\beta$-actin as a loading control. * $\mathrm{p}<0.001$, presence vs. absence of antimycin in MPT cells from $\mathrm{a1}^{-1-}$ mice, $\mathrm{a}^{-/-} \mathrm{KO}$ mice and their WT controls. 
expression was comparable in kidney cortex and MPT cell cultures for both types of AMPK KO mouse versus its WT controls (Figures 3 and 4).

\section{Effect of metabolic stress on activation of the AMPK} pathway in MPT cells from $a 1^{-/-}$and $a 2^{-/-}$mice

We next compared the degree to which AMPK is activated by metabolic stress in MPT cells from AMPK KO versus WT mice. Metabolic stress was induced by treatment of cells with antimycin in the presence of $5 \mathrm{mM}$ dextrose. Activation of AMPK was assessed by immunoblotting for phosphorylation of $\mathrm{Thr}^{172}$ within the catalytic $\alpha$ domain of AMPK. Upon activation, AMPK phosphorylates a number of downstream targets [1,3-5]. As a further measure of AMPK activation, we evaluated the extent of phosphorylation of ACC at $\mathrm{Ser}^{79}$, an event that inhibits ACC activity. We chose ACC, since it is one of the more thoroughly studied downstream targets of AMPK [1].

Treatment with antimycin increased phosphorylation of both AMPK and ACC to a comparable extent in
MPT cells from $\alpha 1^{-1-}$ and $\alpha 2^{-/-}$mice versus their WT controls (Figure 5). These data suggest that the identity of the alpha domain isoform does not influence the degree to which AMPK is activated by antimycin-induced metabolic stress, and that each isoform can substitute for the absence of the other.

Effect of pharmacologic inhibition of AMPK on stress-induced activation of AMPK in MPT cells from AMPK KO and WT mice We examined the effect of compound $C$ (CC), a pharmacologic inhibitor of AMPK, on AMPK activity during metabolic stress in MPT cells from $\alpha 2^{-/-}$and WT mice. Antimycin increased the phosphorylation of both AMPK and its downstream target, ACC, in MPT cells from $\alpha 2^{-/-}$ and WT mice (Figure 6). CC comparably reduced the stress-induced increase in phosphorylation of AMPK and ACC in MPT cells from $\alpha 2^{-/-}$versus WT mice (Figure 6). Similar results, in the absence and presence of CC, were obtained in MPT cells from $\alpha 1^{-/-}$versus WT mice (data not shown).

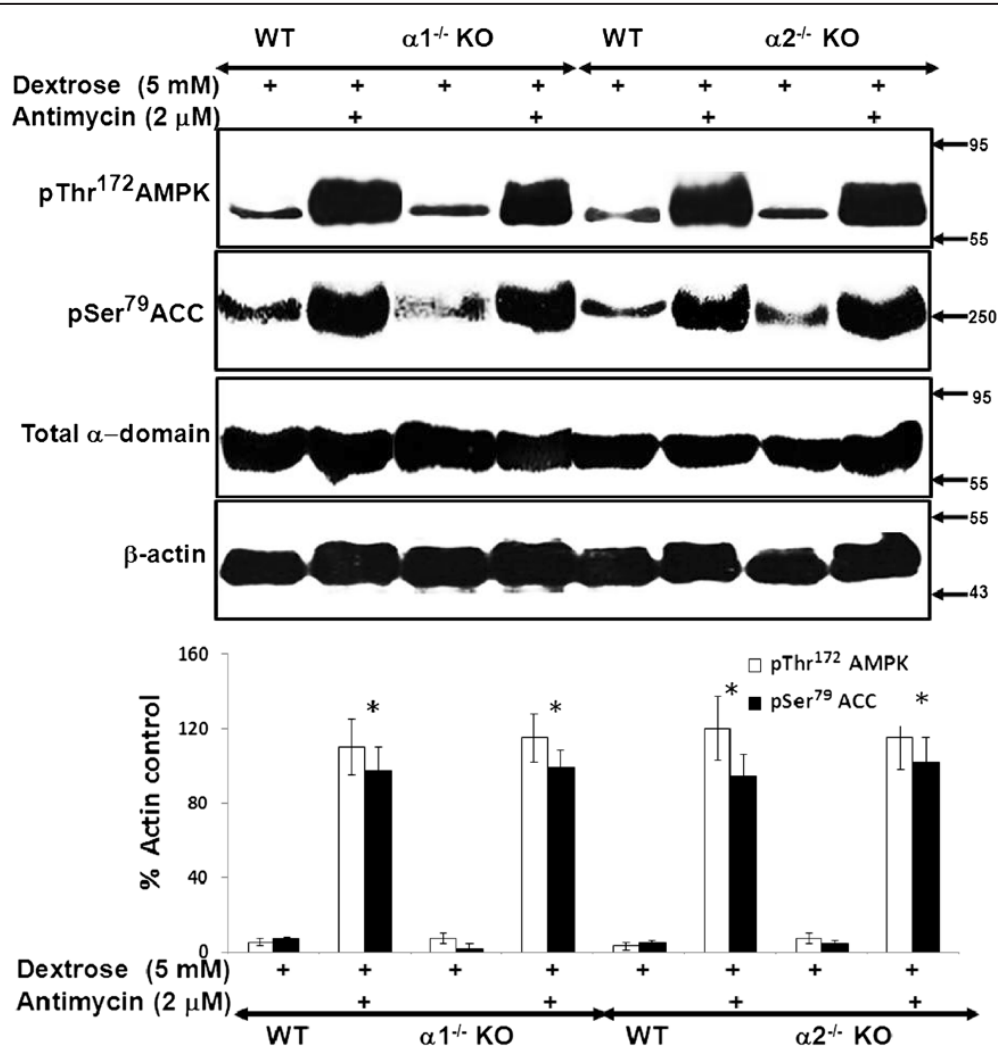

Figure 6 Effect of pharmacologic inhibition of AMPK using compound C (CC) on the activity of the AMPK pathway in MPT cells from $\mathbf{a 2}^{-/-} \mathrm{KO}$ and WT mice. MPT cells from $\mathrm{a}^{-/-}$mice, or their WT control, were subjected to ATP depletion by incubation in medium containing dextrose $(5 \mathrm{mM})$ and antimycin $(2 \mu \mathrm{M})$, in the presence or absence of CC $(20 \mu \mathrm{M})$ for 4 hrs. Activation of the AMPK pathway was assessed by immunoblotting, using antibodies that recognize either the phosphorylated (activated) form of AMPK, or the phosphorylated (inhibited) form of ACC. Expression of total alpha domain was also assessed. Upper panel: Representative immunoblot. Molecular weight markers (in $\mathrm{kDa}$ ) are shown on the right of each immunoblot. Lower panel: Densitometric quantitation of three immunoblots using $\beta$-actin as a loading control. ${ }^{*} p<0.01$, presence vs. absence of CC, for MPT cells from WT mice treated with antimycin; \# $p<0.01$, presence vs. absence of CC, for MPT cells from $\mathrm{a}^{-/-}$mice treated with antimycin. 
Effect of pharmacologic inhibition of AMPK on viability of metabolically stressed MPT cells from AMPK KO and WT mice We next examined the effect of CC on MPT cell viability during metabolic stress. MPT cells from $\alpha 2^{-/-}$mice and their WT controls were subjected to graded ATP depletion (antimycin in the presence of varying concentrations of dextrose) for 16-18 hrs, in the presence of either CC $(20 \mu \mathrm{M})$ or its vehicle. Control cells were incubated in dextrose without antimycin. In the absence of CC, metabolic stress induced a comparable decrease of viability in MPT cells from $\alpha 2^{-1-}$ versus WT mice (Figure 7). Although inhibition of AMPK with CC reduced MPT cell viability at all degrees of metabolic stress, the reduction in viability induced by $\mathrm{CC}$ was comparable in MPT cells from $\alpha 2^{-/-}$versus WT mice (Figure 7). Furthermore, regardless of the presence or absence of CC, ATP levels in metabolically stressed MPT cells did not differ for $\alpha 2^{-/-}$versus WT mice (data not shown). These data are consistent with those of immunoblotting (Figures 5 and 6).

We performed similar experiments using MPT cells from $\alpha 1^{-/-}$versus WT mice. In the absence of CC, metabolic stress (antimycin plus $5 \mathrm{mM}$ dextrose) reduced cell viability to a similar extent in MPT cells from $\alpha 1^{-/-}$versus WT mice $(64 \pm 7 \%$ and $59 \pm 8 \%$ of control, respectively). CC comparably exacerbated the stressinduced loss of cell viability in MPT cells from $\alpha 1^{-/-}$versus WT mice $(35 \pm 6 \%$ and $38 \pm 7 \%$ of control, respectively). Thus, the effects of $\mathrm{CC}$ on the viability of stressed MPT cells was similar for $\alpha 1^{-/-}$and $\alpha 2^{-/-}$mice, as compared to their WT controls.

Effect of knockdown of the $a 2$ isoform on expression and activation of the AMPK pathway in $a 1^{-/-}$and WT mice MPT cells from $\alpha 1^{-/-}$or WT mice were infected with either control (scrambled) shRNA or shRNA designed to knock down expression of the $\alpha 2$ isoform of AMPK. Infection with control shRNA did not alter expression of either the $\alpha 2$ isoform of AMPK or total $\alpha$-domain AMPK in MPT cells from $\alpha 1^{-1-}$ and WT mice (Figure 8). In contrast, infection with anti- $\alpha 2$ shRNA significantly reduced expression of the $\alpha 2$ isoform of AMPK as well as total alpha domain AMPK in MPT cells from both $\alpha 1^{-/-}$and WT mice (Figure 8 ).

We next determined the effect of knockdown of the $\alpha 2$ isoform of AMPK on metabolic stress-induced activation of the AMPK pathway. MPT cell monolayers from $\alpha 1^{-/-}$and WT mice were infected with either control or anti- $\alpha 2$ shRNA. Following infection, MPT cells were incubated in dextrose $(5 \mathrm{mM})$ in the absence or presence of antimycin. In cells infected with control shRNA, metabolic stress induced marked phosphorylation of both AMPK and ACC (Figure 9). Infection with anti- $\alpha 2$ shRNA led to a marked but comparable reduction in phosphorylation of AMPK and ACC in MPT cells from $\alpha 1^{-/-}$versus WT mice (Figure 9).
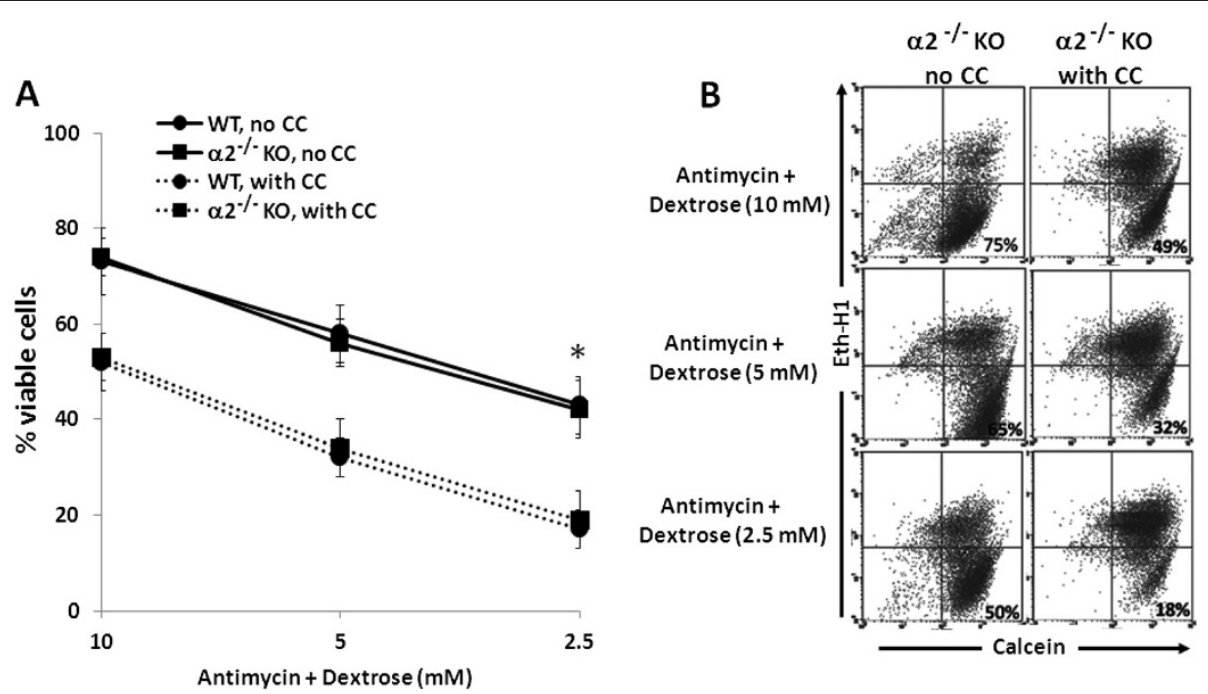

Figure 7 Effect of pharmacologic inhibition of AMPK on viability of MPT cells from $\mathrm{a2}^{-/-} \mathrm{KO}$ and WT mice subjected to metabolic stress. A: MPT cells from $\mathrm{a}^{-1-}$ mice, or their WT control, were subjected to graded ATP depletion by incubation in the presence of antimycin $(2 \mu \mathrm{M})$ and varying concentrations of dextrose for 16-18 hrs, in either the absence (solid lines) or the presence (dashed lines) of CC (20 $\mu \mathrm{M})$. The percentage of viable cells remaining was determined by flow cytometry $(n=5) .{ }^{*} p<0.01$, absence vs. presence of CC, for MPT cells from either $\mathrm{a}^{2^{-/-}}$mice or their WT control (ANOVA for repeated measures). B: Representative flow cytometric analysis of metabolically stressed MPT cells from $\mathrm{a}^{-1-}$ mice incubated in the absence (left panels) or presence (right panels) of CC (20 $\left.\mu \mathrm{M}\right)$. Cell viability was quantified by staining cells with calcein AM (x-axis) and ethidium homodimer-1 (Eth-H1) (y-axis). For each condition, 10,000 cells were analyzed, and the percentage of viable cells was calculated by dividing the number of calcein-positive and Eth-H1-negative cells by the total number of cells counted. 


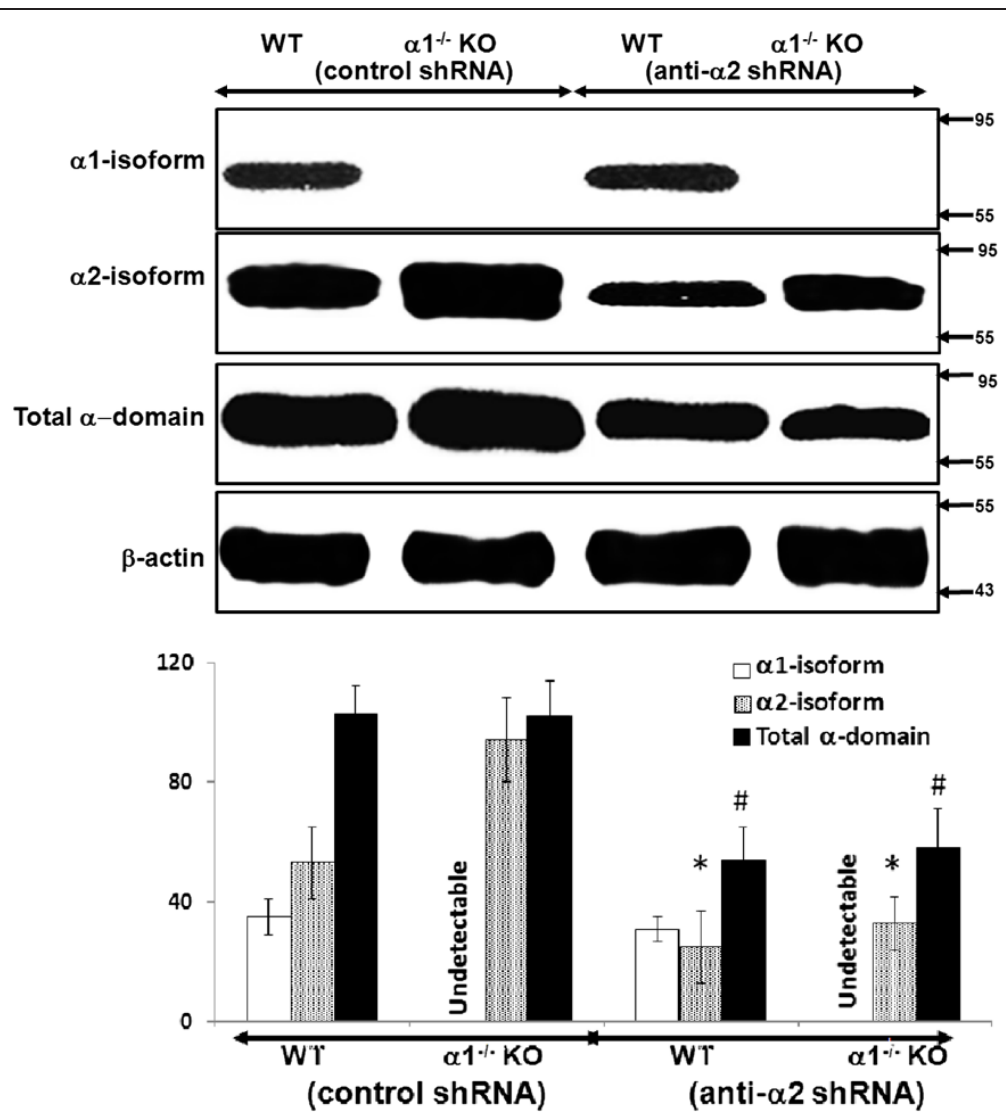

Figure 8 Effect of knockdown of the $a 2$ isoform on expression of the $a 1$ and $a 2$ isoforms and of total alpha domain in MPT cells from $\mathbf{a} \mathbf{1}^{-/-}$and WT mice. MPT cells from $a 1^{-1-}$ mice, or their WT control, were infected with control (scrambled) shRNA or anti-a2 shRNA designed to knock down the expression of the a 2 isoform of AMPK. The relative expression of the a1 and a 2 isoforms of AMPK, as well as of the total a domain $(a 1+a 2)$, was evaluated in immunoblots of lysates from confluent MPT cells derived from the kidneys of $a 1^{-/-}$and $a 2^{-/-}$mice, and their WT controls. Upper panel: Representative immunoblot. Molecular weight markers (in kDa) are shown om the right of each immunoblot. Lower panel: Densitometric quantitation of three immunoblots using $\beta$-actin as a loading control. ${ }^{*} p<0.05$, anti-a2 shRNA vs. control shRNA, for a2 isoform expression in MPT cells from WT and $a 1^{-/-}$mice; $\# p<0.05$, anti-a2 shRNA vs. control shRNA, for total alpha domain expression in MPT cells from $\mathrm{WT}$ and $\mathrm{a}^{-/-}$mice.

Effect of knockdown of the a2 isoform of AMPK on viability of metabolically stressed MPT cells from $a 1^{-/-} \mathrm{KO}$ mice Finally, we examined the effect of knockdown of the $\alpha 2$ isoform of AMPK on the viability of metabolically stressed MPT cells. MPT cells from $\alpha 1^{-/-}$and WT mice were infected with either control shRNA or anti- $\alpha 2$ shRNA, and then incubated in the absence or presence of antimycin plus varying concentrations of dextrose. After 16-18 hrs, the percentage of viable cells was determined by flow cytometry. As with pharmacologic inhibition of AMPK by CC, knockdown of the $\alpha 2$ domain comparably decreased the viability of metabolically stressed MPT cells from $\alpha 1^{-/-}$versus WT mice (Figure 10). Regardless whether cells were infected with control or anti- $\alpha 2$ shRNA, ATP levels did not differ in metabolically stressed MPT cells from $\alpha 1^{-/-}$versus WT mice (data not shown). Taken together, our studies on the effects of AMPK inhibition, accomplished either pharmacologically or molecularly, demonstrate antimycin-induced metabolic stress comparably activates the $\alpha 1$ and $\alpha 2$ isoforms of AMPK, and that either isoform can substitute for the other in ameliorating stress-induced cell death.

\section{Discussion}

Increased activity of AMPK contributes to the pathogenesis of a wide range of diseases, including diabetes mellitus, the metabolic syndrome, neurodegenerative disorders, and cancer [24-30]. However, while an abundance of data indicates that AMPK is activated across multiple cell types during acute ischemic or toxic injury, the contribution by AMPK to cell survival during and following acute injury remains uncertain. Some studies have reported a cytoprotective role for AMPK [31-35], while others have found that AMPK contributes to cell death [12,36-43]. The net effect of AMPK on cell survival likely depends upon multiple variables, including cell lineage, the nature of the 


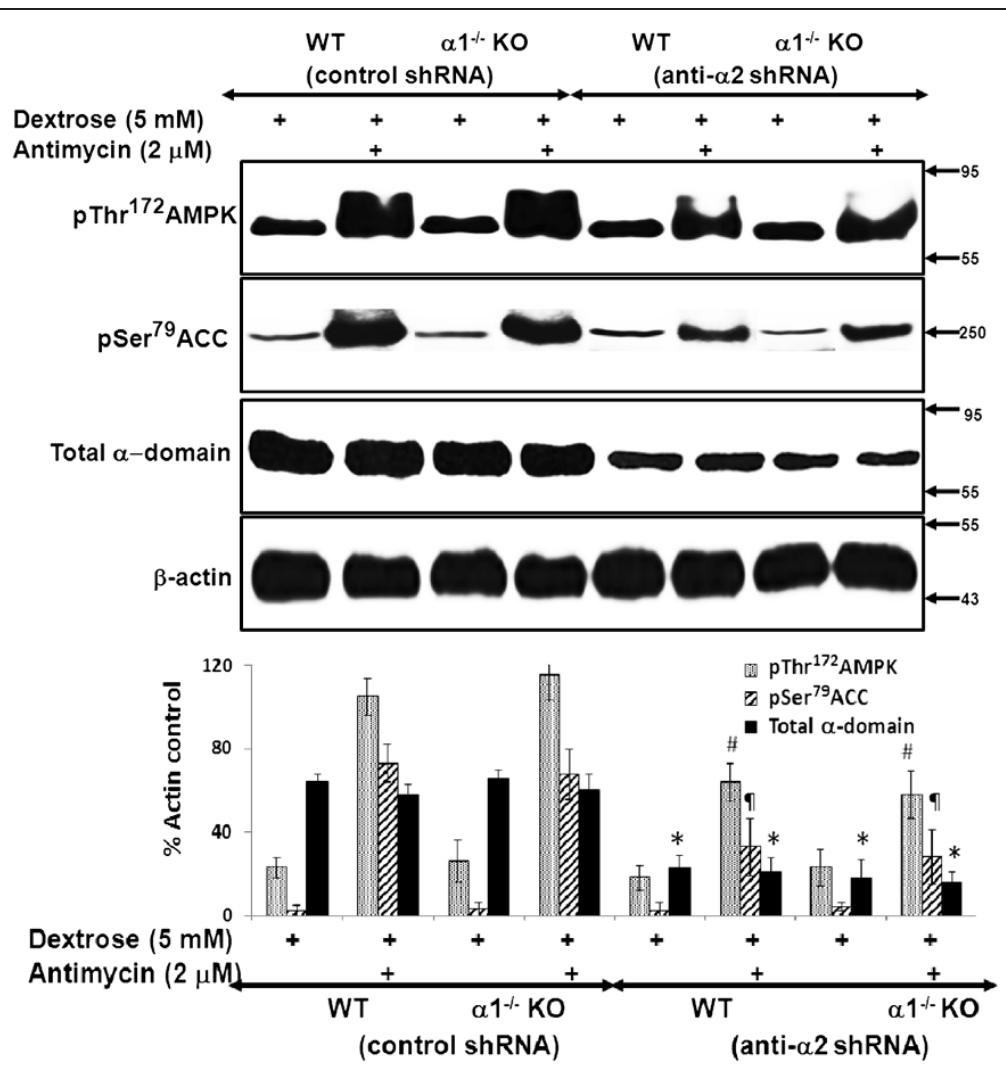

Figure 9 Effect of knockdown of the $a 2$ isoform of AMPK on the activity of the AMPK pathway in MPT cells from a1 ${ }^{-/-}$and WT mice. MPT cells from $\mathrm{a1}^{-1-}$ mice, or their WT control, were infected with control shRNA or anti-a2 shRNA designed to knock down the expression of the a 2 isoform of AMPK. MPT cells were subjected to metabolic stress by incubation in medium containing dextrose ( 5 mM) plus antimycin $(2 \mu \mathrm{M})$ for $4 \mathrm{hrs}$. Control cells were incubated in dextrose in the absence of antimycin. Activation of the AMPK pathway was assessed by immunoblotting using antibodies that recognize either the phosphorylated (activated) form of AMPK or the phosphorylated (inhibited) form of ACC. Expression of total AMPK was also assessed. Upper panel: Representative immunoblot. Molecular weight markers (in kDa) are shown om the right of each immunoblot. Lower panel: Densitometric quantitation of three immunoblots using $\beta$-actin as a loading control. * $p<0.01$, anti-a2 shRNA vs. control shRNA, for total a domain expression in MPT cells from WT or $a 1^{-1-}$ mice; \# $p<0.02$, anti-a2 shRNA vs. control shRNA, for phospho-AMPK expression in MPT cells from WT or $a 1^{-1-}$ mice; $\mathrm{p}<0.02$, anti-a2 shRNA vs. control shRNA, for phospho-ACC expression in MPT cells from WT or $\mathrm{a}^{-1-}$ mice.

toxic stimulus, and the specific pathways responsible for AMPK activation. In the kidney, few data are available, regarding either the state of AMPK activity following ischemic injury, or the role of AMPK in modulating renal tubular cell survival during metabolic stress.

Previously, we have shown that inhibition of AMPK, either pharmacologically (using CC) or via knockdown techniques, increased apoptosis of an immortalized MPT cell line subjected to metabolic stress [18]. These results suggested an anti-apoptotic role for AMPK in metabolically stressed kidney cells. In this study, we tested the hypothesis that primary cultures of MPT cells, derived from AMPK KO mice lacking either the $\alpha 1$ or $\alpha 2$ isoform of the catalytic domain, would be more susceptible to apoptosis induced by metabolic stress than primary MPT cell cultures from their WT controls. To our surprise, stress-induced death was no more severe in MPT cells from KO mice compared MPT cells from the
WT controls (Figure 1). Moreover, while treatment of MPT cells with antimycin in the presence of decreasing concentrations of dextrose led to a progressive fall in cell ATP levels (Figure 2), the decrease in cell ATP levels at every degree of metabolic stress was comparable in $\mathrm{KO}$ versus WT mice (Figure 2).

Our data suggest that the lack of difference in susceptibility to stress-induced death by MPT cells from AMPK KO versus WT mice is related to a compensatory increase in the expression of the non-deleted alpha isoform that occurs in the kidney cortex (Figure 3) and MPT cell cultures (Figure 4) from $\alpha 1^{-/-}$and $\alpha 2^{-/-}$mice. Thus, expression of the $\alpha 2$ isoform of AMPK is upregulated in the cortex (Figure 3) and primary MPT cell cultures (Figure 4) from the kidneys of $\alpha 1^{-/-}$mice. Similarly, expression of the $\alpha 1$ isoform is up-regulated in the cortex (Figure 3) and primary MPT cell cultures (Figure 4) from the kidneys of $\alpha 2^{-/-}$mice. As a result, total $\alpha-$ 

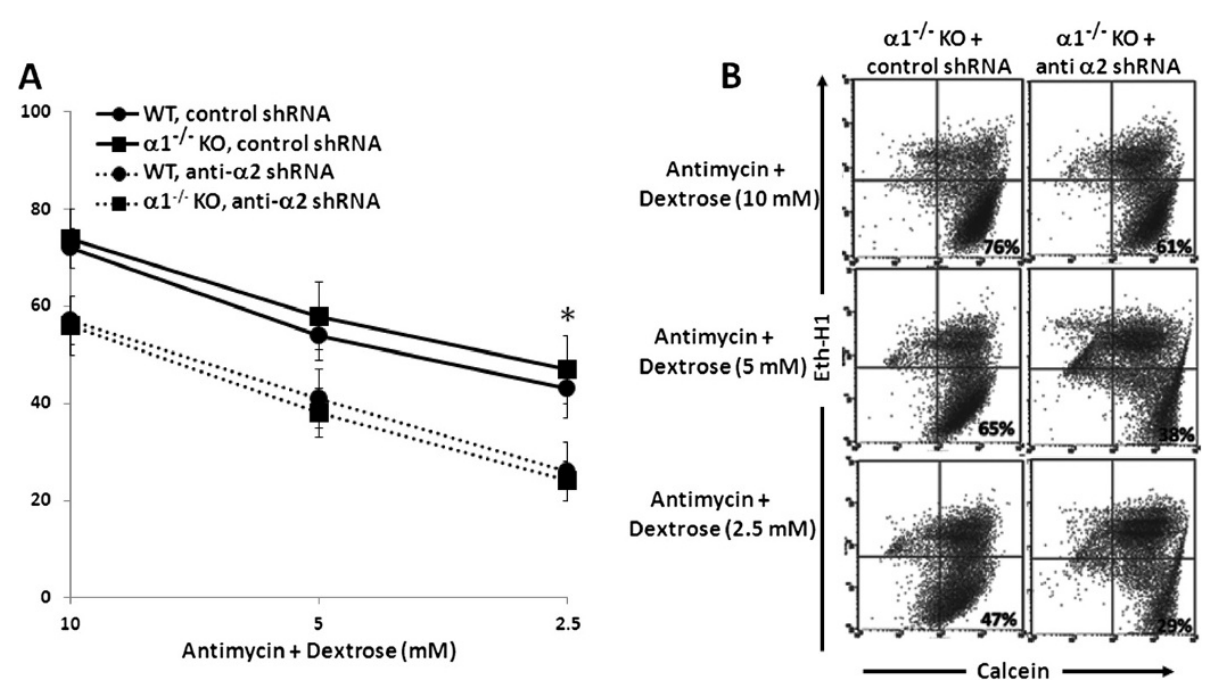

Figure 10 Effect of knockdown the $\mathrm{a} 2$ isoform of AMPK on the viability of MPT cells from $\mathrm{a}^{-/-} \mathrm{KO}$ and WT mice subjected to metabolic stress. A: MPT cells from $a 1^{-1-}$ mice, or their WT control, were infected with control shRNA (solid lines) or anti-a2 shRNA designed to knock down the expression of the a2 isoform of AMPK (dashed lines). Cells were then subjected to graded ATP depletion by incubation for 16-18 hrs in the presence of antimycin $(2 \mu \mathrm{M})$ and varying concentrations of dextrose. The percentage of viable cells remaining was determined by flow cytometry $(n=5) .{ }^{*} p<0.01$, anti-a2 shRNA vs. control shRNA, for MPT cells from $a 1^{-1-}$ or WT mice (ANOVA for repeated measures). B: Representative flow cytometric analysis of metabolically stressed MPT cells from $a 2^{-1-}$ mice infected with anti-a2 shRNA (right panels) or control shRNA (left panels). Cell viability was quantified by staining cells with calcein AM ( $\mathrm{x}$-axis) and ethidium homodimer-1 (Eth-H1) ( $y$-axis). For each condition, 10,000 cells were analyzed, and the percentage of viable cells was calculated by dividing the number of calcein-positive and Eth-H1-negative cells by the total number of cells counted.

domain expression ( $\alpha 1+\alpha 2$ isoforms) is comparable in AMPK KO versus WT mice.

We next examined the effect of metabolic stress on the phosphorylation, not only of the $\alpha$-domain of AMPK, but also of ACC, an immediate downstream target of AMPK that has been widely used as a marker of AMPK activity [1]. Interestingly, metabolic stress induced comparable degrees of phosphorylation of AMPK and ACC in MPT cells from $\alpha 1^{-/-}$mice, $\alpha 2^{-/-}$mice and both of their WT controls (Figure 5). These findings suggest that equivalent expression of the total $\alpha$-domain by $\mathrm{KO}$ and WT mice is matched by functional equivalence of AMPK activity.

We suggest that the lack of a difference in susceptibility to antimycin-induced cell death by MPT cells derived from $\alpha 1^{-/-}$and $\alpha 2^{-/-}$mice versus their WT controls is attributable to an adaptive equivalence in the amount and activity of the total alpha isoform of AMPK in MPT cells from the KO and WT mice. We further suggest that that each $\alpha$ isoform can substitute for the other in phosphorylation of downstream targets and in mediating the anti-apoptotic functions of AMPK. This interpretation is supported by studies in which we examined the effects of inhibiting AMPK in primary cultures of MPT cells from the AMPK KO and WT mice. Pharmacological inhibition of AMPK (using CC) of MPT cells from AMPK KO and WT mice, reduced the antimycininduced phosphorylation of AMPK and ACC (Figure 6), and exacerbated the stress-induced death of MPT cells from the $\mathrm{KO}$ and WT mice (Figure 7). However, the extent to which CC inhibited AMPK phosphorylation (Figure 6), or worsened MPT cell death (Figure 7), was not different between MPT cells derived from the KO and WT mice. Similarly, inhibiting AMPK in MPT cells obtained from $\alpha 1^{-1-}$ mice and their WT controls by knocking down the $\alpha 2$ isoform using shRNA, decreased antimycin-induced phosphorylation of AMPK and ACC (Figure 9), and exacerbated the amount of death of MPT cells (Figure 10) obtained from both the $\mathrm{KO}$ and WT mice to a comparable degree.

Our data show that while genetic deletion of either the $\alpha 1$ or $\alpha 2$ isoform of AMPK does not affect the response of MPT cells to metabolic stress, inhibition of AMPK induced by $\mathrm{CC}$ or molecular knockdown markedly increases the susceptibility of MPT cells from WT and KO mice to metabolic stress. It is likely that the compensatory increase in expression of the non-deleted $\alpha$-isoform occurring in AMPK KO mice is due to increased protein synthesis. We speculate that, in the case of acute inhibition of AMPK, either by CC or molecular knockdown, there is insufficient time for a compensatory increase of protein synthesis of alpha isoforms to occur.

It is important to note that our results do not exclude the possibility that the various isoforms of AMPK may differ in role and function in different tissues $[1,30]$. To date, very little data exist on the consequences of genetic 
deletion of one isoform on the expression and activity of the other isoform(s). Our results indicate that any attempt to link a particular phenotype (or lack of phenotype) with the absence of one or other of the isoforms of AMPK should be done with caution, since expression and activity of the remaining isoform may be subject to an adaptive up-regulation.

\section{Conclusions}

Our study has several major conclusions. First, primary cultures of mouse proximal tubular (MPT) cells from both $\alpha 1^{-/-}$and $\alpha 2^{-/-}$mice demonstrate an adaptive increase in expression of the intact $\alpha$-domain isoform of AMPK, such that total $\alpha$-domain expression is comparable in KO versus WT mice. Second, the $\alpha 1$ and $\alpha 2$ isoforms of AMPK are equally sensitive to metabolic stress, since exposure to antimycin led to comparable increases of AMPK activity in primary MPT cells from $\alpha 1^{-/-}$and $\alpha 2^{-/-}$mice. Third, the $\alpha 1$ and $\alpha 2$ isoforms of AMPK provide equivalent protection from stress-induced cell death, since primary MPT cells from $\alpha 1^{-/-}$and $\alpha 2^{-/-}$ mice versus their WT controls were equally susceptible to cell death from ATP depletion. Moreover, the use of compound $C$ to inhibit the activity of the $\alpha 1$ or the $\alpha 2$ isoform in primary MPT cells derived from $\alpha 2^{-/-}$and $\alpha 1^{-/-}$mice respectively, or the inhibition of the $\alpha 2$ isoform in primary MPT cells from $\alpha 1^{-/-}$mice (via molecular knockdown) both exacerbated loss of cell viability in response to ATP depletion to the same degree. Taken together, these data suggest that the $\alpha 1$ - and $\alpha 2$-isoforms of AMPK are not only similarly activated by ATP depletion, but also similarly effective in reducing cell death during metabolic stress. The adaptive up-regulation of the intact isoform of AMPK in KO mice is consistent with an overall critical role for AMPK in ameliorating apoptosis of proximal tubular cells in response to acute reductions of cellular ATP during ischemia.

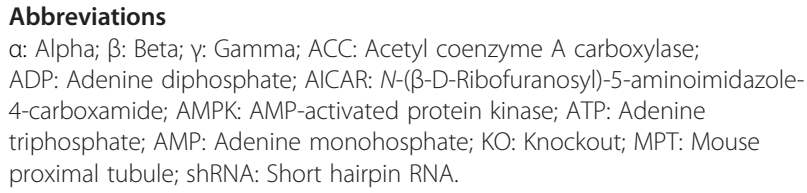

\section{Competing interests}

The authors declare that they have no competing interest.

\section{Authors' contributions}

$L Z, M T$, and VP all contributed substantially to the generation of the data presented in this study. BV provided expert advice regarding the execution and interpretation of this study. WL and JSL contributed equally to the planning of studies and to writing of the manuscript. All authors read and approved the final manuscript.

\section{Acknowledgements}

W. Lieberthal was supported by a Veterans Affairs Merit Award and by awards from Dialysis Clinic, Inc. (DCI) (C-3176, C-2243 and C3351).

\section{Author details}

${ }^{1}$ Department of Medicine, Stony Brook University Medical Center, Stony Brook, NY 11794, USA. ${ }^{2}$ Northport Veterans Affairs Medical Center, Northport, NY 11768, USA. ${ }^{3}$ Inserm, U1016, Institut Cochin, Paris, France. ${ }^{4}$ CNRS, UMR 8104, Paris, France. ${ }^{5}$ Université Paris Descartes, Sorbonne Paris Cité, Paris, France. ${ }^{6}$ Department of Medicine, University of Illinois at Chicago, Chicago, IL 60612, USA. ${ }^{7}$ Jesse Brown Veterans Affairs Medical Center, Chicago, IL 60612, USA.

Received: 30 May 2013 Accepted: 6 November 2013

Published: 14 November 2013

\section{References}

1. Hardie DG, Ross FA, Hawley SA: AMPK: a nutrient and energy sensor that maintains energy homeostasis. Nat Rev Mol Cell Biol 2012, 13(4):251-262.

2. Steinberg GR, Kemp BE: AMPK in health and disease. Physiol Rev 2009, 89(3):1025-1078.

3. Hardie DG: Signal transduction: how cells sense energy. Nature 2011, 472(7342):176-177.

4. Bland ML, Birnbaum MJ: Cell biology. ADaPting to energetic stress. Science 2011, 332(6036):1387-1388.

5. Woods A, Johnstone SR, Dickerson K, Leiper FC, Fryer LG, Neumann D, et al: LKB1 is the upstream kinase in the AMP-activated protein kinase cascade. Curr Biol 2003, 13(22):2004-2008.

6. Xiao B, Sanders MJ, Underwood E, Heath R, Mayer FV, Carmena D, et al: Structure of mammalian AMPK and its regulation by ADP. Nature 2011, 472(7342):230-233.

7. Oakhill JS, Steel R, Chen ZP, Scott JW, Ling N, Tam S, et al: AMPK is a direct adenylate charge-regulated protein kinase. Science 2011, 332(6036):1433-1435

8. Carling D: The AMPK-activated protein kinase cascade - a unifying system for energy control. Trends Biochem Sci 2004, 29:18-24.

9. Hardie DG: AMP-activated/SNF1 protein kinases: conserved guardians of cellular energy. Nat Rev Mol Cell Biol 2007, 8(10):774-785.

10. Hardie DG, Carling D: The AMP-activated protein kinase-fuel gauge of the mammalian cell? Eur J Biochem 1997, 246(2):259-273.

11. Hardie DG: AMP-activated protein kinase: the guardian of cardiac energy status. J Clin Invest 2004, 114(4):465-468.

12. Hallows KR, Mount PF, Pastor-Soler NM, Power DA: Role of the energy sensor AMP-activated protein kinase in renal physiology and disease. Am J Physiol Renal Physiol 2010, 298:F1067-F1077.

13. Hue L, Beauloye C, Bertrand L, Horman S, Krause U, Marsin AS, et al: New targets of AMP-activated protein kinase. Biochem Soc Trans 2003, 31(Pt 1):213-215.

14. Hardie DG, Carling D, Carlson M: The AMP-activated/SNF1 protein kinase subfamily: metabolic sensors of the eukaryotic cell? Annu Rev Biochem 1998, 67:821-855.

15. Hardie DG, Pan DA: Regulation of fatty acid synthesis and oxidation by the AMP-activated protein kinase. Biochem Soc Trans 2002, 30(Pt 6):1064-1070.

16. Hay N, Sonenberg N: Upstream and downstream of mTOR. Genes Dev 2004, 18(16):1926-1945.

17. Gwinn DM, Shackelford DB, Egan DF, Mihaylova MM, Mery A, Vasquez DS, et al: AMPK phosphorylation of raptor mediates a metabolic checkpoint. Mol Cell 2008, 30(2):214-226.

18. Lieberthal W, Zhang L, Patel VA, Levine JS: AMPK protects proximal tubular cells from stress-induced apoptosis by an ATP-independent mechanism: potential role of Akt activation. Am J Physiol Renal Physiol 2011, 301(6):F1177-F1192.

19. Viollet B, Andreelli F, Jorgensen SB, Perrin C, Geloen A, Flamez D, et al: The AMP-activated protein kinase alpha2 catalytic subunit controls whole-body insulin sensitivity. J Clin Invest 2003, 111(1):91-98.

20. Jorgensen SB, Viollet B, Andreelli F, Frosig C, Birk JB, Schjerling P, et al: Knockout of the alpha2 but not alpha1 5'-AMP-activated protein kinase isoform abolishes 5-aminoimidazole-4-carboxamide-1-beta-4ribofuranosidebut not contraction-induced glucose uptake in skeletal muscle. J Biol Chem 2004, 279(2):1070-1079.

21. Kroshian VM, Sheridan AM, Lieberthal W: Functional and cytoskeletal changes induced by sublethal injury in proximal tubular epithelial cells. Am J Physiol 1994, 266(1 Pt 2):F21-F30. 
22. Lieberthal W, Menza SA, Levine JS: Graded ATP depletion can cause necrosis or apoptosis of cultured mouse proximal tubular cells. Am J Physiol 1998, 274(2 Pt 2):F315-F327.

23. Sinha D, Wang Z, Ruchalski KL, Levine JS, Krishnan S, Lieberthal W, et al: Lithium activates the Wnt and phosphatidylinositol 3-kinase Akt signaling pathways to promote cell survival in the absence of soluble survival factors. Am J Physiol Renal Physiol 2005, 288(4):F703-F713.

24. Gruzman A, Babai G, Sasson S: Adenosine monophosphate-activated protein kinase (AMPK) as a New target for antidiabetic drugs: a review on metabolic, pharmacological and chemical considerations. Rev Diabet Stud 2009, 6(1):13-36.

25. Mori H, Inoki K, Masutani K, Wakabayashi Y, Komai K, Nakagawa R, et al: The mTOR pathway is highly activated in diabetic nephropathy and rapamycin has a strong therapeutic potential. Biochem Biophys Res Commun 2009, 384(4):471-475.

26. Luo Z, Saha AK, Xiang $X$, Ruderman NB: AMPK, the metabolic syndrome and cancer. Trends Pharmacol Sci 2005, 26(2):69-76.

27. Kola B, Boscaro M, Rutter GA, Grossman AB, Korbonits M: Expanding role of AMPK in endocrinology. Trends Endocrinol Metab 2006, 17(5):205-215.

28. Musi N, Goodyear LJ: Targeting the AMP-activated protein kinase for the treatment of type 2 diabetes. Curr Drug Targets Immune Endocr Metabol Disord 2002, 2(2):119-127.

29. Kato K, Ogura T, Kishimoto A, Minegishi $Y$, Nakajima N, Miyazaki M, et al: Critical roles of AMP-activated protein kinase in constitutive tolerance of cancer cells to nutrient deprivation and tumor formation. Oncogene 2002, 21(39):6082-6090.

30. Arad M, Seidman CE, Seidman JG: AMP-activated protein kinase in the heart: role during health and disease. Circ Res 2007, 100(4):474-488.

31. Russell RR 3rd, Li J, Coven DL, Pypaert M, Zechner C, Palmeri M, et al: AMPactivated protein kinase mediates ischemic glucose uptake and prevents postischemic cardiac dysfunction, apoptosis, and injury. J Clin Invest 2004, 114(4):495-503.

32. Spector NL, Yarden $Y$, Smith B, Lyass L, Trusk P, Pry K, et al: Activation of AMP-activated protein kinase by human EGF receptor 2/EGF receptor tyrosine kinase inhibitor protects cardiac cells. Proc Natl Acad Sci U S A 2007, 104(25):10607-10612.

33. Shibata R, Sato K, Pimentel DR, Takemura Y, Kihara S, Ohashi K, et al: Adiponectin protects against myocardial ischemia-reperfusion injury through AMPK- and COX-2-dependent mechanisms. Nat Med 2005, 11(10):1096-1103.

34. Terai K, Hiramoto Y, Masaki M, Sugiyama S, Kuroda T, Hori M, et al: AMPactivated protein kinase protects cardiomyocytes against hypoxic injury through attenuation of endoplasmic reticulum stress. Mol Cell Biol 2005, 25(21):9554-9575.

35. Peralta C, Bartrons R, Serafin A, Blazquez C, Guzman M, Prats N, et al: Adenosine monophosphate-activated protein kinase mediates the protective effects of ischemic preconditioning on hepatic ischemiareperfusion injury in the rat. Hepatology 2001, 34(6):1164-1173.

36. Li J, Zeng Z, Viollet B, Ronnett GV, McCullough LD: Neuroprotective effects of adenosine monophosphate-activated protein kinase inhibition and gene deletion in stroke. Stroke 2007, 38(11):2992-2999.

37. McCullough LD, Zeng Z, Li H, Landree LE, McFadden J, Ronnett GV: Pharmacological inhibition of AMP-activated protein kinase provides neuroprotection in stroke. J Biol Chem 2005, 280(21):20493-20502.

38. Cao C, Lu S, Kivlin R, Wallin B, Card E, Bagdasarian A, et al: AMP-activated protein kinase contributes to UV- and $\mathrm{H} 2 \mathrm{O} 2$-induced apoptosis in human skin keratinocytes. J Biol Chem 2008, 283(43):28897-28908.

39. Memmott RM, Gills JJ, Hollingshead M, Powers MC, Chen Z, Kemp B, et al: Phosphatidylinositol ether lipid analogues induce AMP-activated protein kinase-dependent death in LKB1-mutant non small cell lung cancer cells. Cancer Res 2008, 68(2):580-588.

40. Okoshi R, Ozaki T, Yamamoto H, Ando K, Koida N, Ono S, et al: Activation of AMP-activated protein kinase induces p53-dependent apoptotic cell death in response to energetic stress. J Biol Chem 2008, 283(7):3979-3987.

41. Shaw MM, Gurr WK, McCrimmon RJ, Schorderet DF, Sherwin RS: 5'AMPactivated protein kinase alpha deficiency enhances stress-induced apoptosis in BHK and PC12 cells. J Cell Mol Med 2007, 11(2):286-298.
42. Tzatsos A, Tsichlis PN: Energy depletion inhibits phosphatidylinositol 3-kinase/Akt signaling and induces apoptosis via AMP-activated protein kinase-dependent phosphorylation of IRS-1 at Ser-794. J Biol Chem 2007, 282(25):18069-18082.

43. Dagon Y, Avraham Y, Berry EM: AMPK activation regulates apoptosis, adipogenesis, and lipolysis by elF2alpha in adipocytes. Biochem Biophys Res Commun 2006, 340(1):43-47.

doi:10.1186/1471-2369-14-251

Cite this article as: Lieberthal et al: Susceptibility to ATP depletion of primary proximal tubular cell cultures derived from mice lacking either the $a_{1}$ or the $a 2$ isoform of the catalytic domain of AMPK. BMC Nephrology 2013 14:251.

\section{Submit your next manuscript to BioMed Central and take full advantage of:}

- Convenient online submission

- Thorough peer review

- No space constraints or color figure charges

- Immediate publication on acceptance

- Inclusion in PubMed, CAS, Scopus and Google Scholar

- Research which is freely available for redistribution

Submit your manuscript at www.biomedcentral.com/submit
C) BioMed Central 